University of Nebraska - Lincoln

DigitalCommons@University of Nebraska - Lincoln

Double cropping opportunities for biomass crops in the north central USA

Kenneth J. Moore

lowa State University, kjmoore@iastate.edu

Douglas L. Karlen

USDA-ARS, doug.karlen@ars.usda.gov

Follow this and additional works at: https://digitalcommons.unl.edu/usdaarsfacpub

Moore, Kenneth J. and Karlen, Douglas L., "Double cropping opportunities for biomass crops in the north central USA" (2013). Publications from USDA-ARS / UNL Faculty. 1647.

https://digitalcommons.unl.edu/usdaarsfacpub/1647

This Article is brought to you for free and open access by the U.S. Department of Agriculture: Agricultural Research Service, Lincoln, Nebraska at DigitalCommons@University of Nebraska - Lincoln. It has been accepted for inclusion in Publications from USDA-ARS / UNL Faculty by an authorized administrator of DigitalCommons@University of Nebraska - Lincoln. 


\title{
Double cropping opportunities for biomass crops in the north central USA
}

\author{
Biofuels (2013) 4(6), 605-615
}

\begin{abstract}
Kenneth J Moore*1 \& Douglas L Karlen ${ }^{2}$
Increased biomass crop production is essential for the development of sustainable bioenergy and bioproduct industries. Double cropping is one strategy that may help meet those goals, but in more northern latitudes traditional double cropping has been limited by a short growing season. However, since lignocellulosic biomass crops do not need to complete their lifecycle and produce seed, double cropping those species could be successful and provide several beneficial ecosystem services. This includes providing nearly year-round ground cover to reduce soil exposure to water and wind erosion, and diversifying landscapes to help mitigate the unintended consequences of many current agricultural practices. Double cropping could also offer management flexibility in response to weather and market factors, provided the net return is commensurate with current singlecrop, grain production practices. Currently available double crop information for the north central region of the USA is limited, so we conclude that such R\&D is warranted.
\end{abstract}

Although soil and crop management research per se is neither a new nor a recently recognized research topic, soil and water resources are continuing to be degraded due to the unintended consequences of several current agricultural management practices. New and innovative soil and crop management strategies must be developed in order to mitigate these consequences, but in order to be adopted by producers, there must be sufficient market pull to make the strategies economically viable when compared with established grain production and marketing systems. Market pull could potentially be accomplished by linking new agricultural management practices to the emerging bioeconomy, since development of economically viable, productive and socially acceptable biomass feedstock supplies is crucial for meeting global energy needs [1], helping alleviate international food versus fuel conflicts [2], and sustaining soil, water and air resources.

This Special Report examines one soil and crop management strategy - double crop biomass production - in the northern portion of the US corn/soybean belt.
Double crop biomass production is a relatively new focus for agriculture in this region, driven by the need to provide lignocellulosic feedstocks for bioenergy plants that are currently under construction, and as such should not be confused with prior studies on double cropping for grain production. As a new focus for soil and crop management studies in this region, there are nearly an endless number of double crop permutations involving different crop sequences, specific end uses, soil health implications, pest compatibilities and profit potentials that could be examined as strategies for improved soil and water conservation. However, at this point in time, attempting to anticipate which combinations could have the highest environmental, economic and social impact would simply be an academic exercise in predicting the future. Therefore, our goal is to simply look forward at the potential for using double crop strategies to increase bioenergy crop production. Finally, although published literature on this specific topic is somewhat limited, a diligent effort is made in this article to locate all relevant references 


\section{Key terms}

Crop biomass: All of the aboveground dry matter produced by a crop, may include grain as well as vegetative structures.

Corn/soybean belt: An agricultural region in midwestern USA where corn and soybean are the dominant crops. This area extends from eastern Nebraska to western Ohio, and from northern Missouri into southern Minnesota.

Double cropping: Farming practice that involves producing two crops in succession on the same land within a single growing season.

Lignocellulosic biomass: Biomass that is predominantly vegetative when harvested. It is generally composed of leaves and stems, but can also include other vegetative structures associated with grain development, such as husks and cobs, when applied to crop residues. Chemically, it consists primarily of cellulose, hemicellulose and lignin. and to augment published information with recent, unpublished data from our personal ongoing research programs.

Plant biomass has been important to humans for centuries because of its use for a variety of applications, including fuel for warmth and cooking, lumber and other building materials, textiles and papermaking [3]. Recently, the focus for biomass crops has been on bioenergy production, but with increasing emphasis on green chemistry endeavors defined as the design of chemical products and processes that reduce or eliminate the use or generation of hazardous substances [4] - the demand for biobased products such as plant-based plastics, textiles and pharmaceuticals will likely increase. For biofuel or electricity production, feedstock cost typically represents two-thirds or more of the product cost [5]; therefore, developing more costeffective biomass crop production systems is essential. Double cropping, a farming practice that involves producing two crops in succession on the same land within a single growing season, is one strategy that needs to be examined for its ability to help meet these goals. In addition to helping meet increased market demand for biomass crops, the potential environmental benefits of developing and facilitating the adoption of double cropping practices for increased lignocellulosic supplies may actually be one of the most important soil and crop management changes producers and conservationists can make, because of the potential impact these practices could have on soil health and quality [6].

One example of how biomass double crop systems can have positive environmental benefits is through their effect on soil carbon stocks. Traditional grain cropping and fallow periods, especially if practiced using conventional tillage practices, often results in a net loss of soil carbon (organic matter) and a slow degradation of soil health as reflected by changes in physical, chemical and biological properties and processes. Double crop biomass production could reverse this trend by providing additional carbon to the soil through increased root mass, as well as soil cover during periods when soils under current production practices are often left bare and exposed to soil erosion.

The central importance of developing crop management practices that sustain soil resources was recently recognized internationally through the launch of a Soil Carbon Initiative by the United States Studies Centre and the Faculty of Agriculture at the University of Sydney (Sydney, Australia) [7]. That initiative focuses on the maintenance and improvement of soils worldwide so that they can continue to provide food, feed, fiber and freshwater, contribute to energy and climate sustainability, and help to maintain biodiversity and protect ecosystem goods and services. Increased production of lignocellulosic biomass crops potentially offers many environmental benefits that can contribute to the sustainability of soil resources. Some examples include: fossil fuel displacement, lower emissions of GHGs and other air pollutants, enhanced soil quality, reduced soil erosion, reduced nutrient runoff and enhanced biodiversity [3]. Demirbas, Rowe et al. Anjum, and Skinner et al. provide more detailed reviews and discussion of these and other potential benefits [8-11].

Increased biomass crop production, using practices such as double cropping, has the potential to promote rural economic activity within several sectors [3]. Farmers would have increased demand for their products, including crop residues from existing crops, because double cropping would ensure the land was not bare and exposed to erosive forces between crops. Farmers and/or those using biomass crops would also be able to employ additional workers to collect, transport and store the feedstocks. Farmers would also be able to make better use of degraded or marginal land not suitable for grain production.

The broader environmental and social impacts of biomass crop production are by no means guaranteed, because the real drivers depend upon how any given biomass crop production system is designed and implemented. For example, detractors of bioenergy production systems have called into question its sustainability, citing a number of concerns including: food versus fuel, land-use change (direct and indirect), water use, invasive species and biodiversity, to mention just a few. These issues have resulted in many productive debates (e.g., Rosillo-Calle and Johnson [2]) and have prompted an ever-expanding literature base focused on analyzing and discussing the keys to 'getting biofuels right' so that the promise of sustainable bioenergy can be realized [12-14]. Double cropping is simply one strategy for helping to minimize both competition with food production and land-use change effects. Its potential in the north central USA is the focus for this evaluation with discussion of these broad sustainability issues being beyond the scope of our assessment.

An increased awareness of the environmental importance of developing sustainable biomass crop production systems to support biofuel industries is also evident when comparing the original Billion Ton Study [15] with the Revised Billion Ton Report [16]. The Billion Ton Study adequately assessed potential wind and water 
erosion impacts of producing a variety of biomass feedstock materials, but failed to examine soil carbon and nutrient balance with equal rigor. This was rectified in the Revised Billion Ton Report and is an integral part of many emerging sustainability assessment tools such as the Landscape Environmental Assessment Framework [101]. The focus for the remainder of this assessment, double cropping, is just one example of what entire volumes are being written about.

\section{Double cropping}

Double cropping involves producing two crops in succession on the same land within a growing season [17]. Sometimes the definition is written more broadly to include any cropping system that produces two crops from the same land within a single growing season without regard to the timing of production. However, for the purpose of this article, we will adhere to the former definition where two distinct crops are produced in two separate time periods within a growing season.

The rationale for double cropping is to better exploit the growing season by using a sequence of crops that are better adapted to specific growing periods within a season (Figure 1). Thus, in areas with an extended growing season and mild winters, it is possible to increase overall productivity by harvesting two crops from the same land area. According to Helsel and Wedin, double cropping in the USA has been most successful east of $90^{\circ}$ west and south of $40^{\circ}$ north [18].

Harvesting crops for biomass reduces the length of the growing period required because neither crop needs to reach reproductive maturity. Maximum accumulation of biomass occurs well ahead of grain ripening in most crops and, therefore, a shorter growing period is required to optimize production. This provides increased flexibility in the management of the two crops and can significantly decrease the total growing season required to produce two sequential crops. Thus, production of biomass using a double crop system could potentially be extended into more northern latitudes than are typical for these systems. For the purpose of this article, we will be focusing on double crop biomass production systems for the north central USA (i.e., above latitude $40^{\circ} \mathrm{N}$ ). This region encompasses a high concentration of prime cropland and benefits from a humid continental climate. Soils in this region vary widely in productivity, but in general are inherently fertile [19]. The region encompasses US Department of Agriculture hardiness zones 3-5 with growing seasons ranging from 120 to 210 days [20]. These climatic and edaphic characteristics combine to create and define one of the world's most productive agricultural regions [21].

Yield data collected for two crops, winter rye (Secale cereale L.) and sorghum (Sorghum bicolor [L.] Moench), at approximately $42^{\circ} \mathrm{N}$ demonstrate the potential for double cropping in the northern part of the Corn Belt [KJ Moore, Dl Karlen, Unpublished Data]. Winter rye was seeded in late October 2010 and 2011, and harvested in the third week of May. Sorghum was planted in the third week of May in 2010 and the second week in 2011. Two sorghum varieties were grown: a sweet sorghum that accumulates sucrose in vegetative plant parts, primarily stems, and a forage hybrid. Both varieties were harvested in early October 2011 and late September 2012. Although these crops were produced in different fields, the timing of their production was such that they could have been produced sequentially on the same land. The weather experienced during the two growing seasons provided a stark contrast with rainfall and temperature patterns, in 2011 being close to the long-term average and in 2012 being much warmer and drier. Combined biomass yields of the two crops were close to or over $25 \mathrm{Mg} / \mathrm{ha}$ in both years (Figure 2). Yield of rye was much greater in the second year of production due to more favorable growing conditions in early spring. However, sorghum yields were lower, reflecting the moisture stress that occurred later in the growing season. The consequence of this was that the differences in the combined yield between the two growing seasons was smaller than for either crop. This illustrates yet another potential advantage of a double crop system; the ability to stabilize production through differential responses of the crops to prevailing weather patterns. This brief example demonstrates the potential of a double energy crop system to produce relatively high yields.

Double cropping of bioenergy feedstock crops has the potential to become an important soil and crop management strategy for simultaneously improving soil quality and producing biomass feedstocks, because

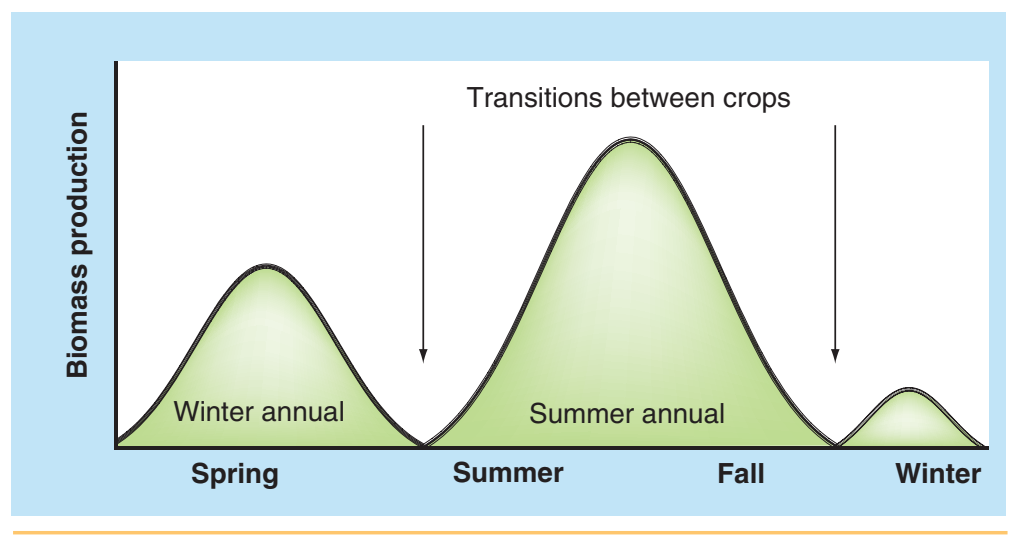

Figure 1. Biomass production for a double-crop sequence using a winter annual crop followed by a summer annual crop to extend the growing season and duration of soil cover. The risk of nutrient leaching is greatest in the periods between crops. Double cropping reduces leaching potential and shifts the period of highest risk to later in the growing season [29]. 


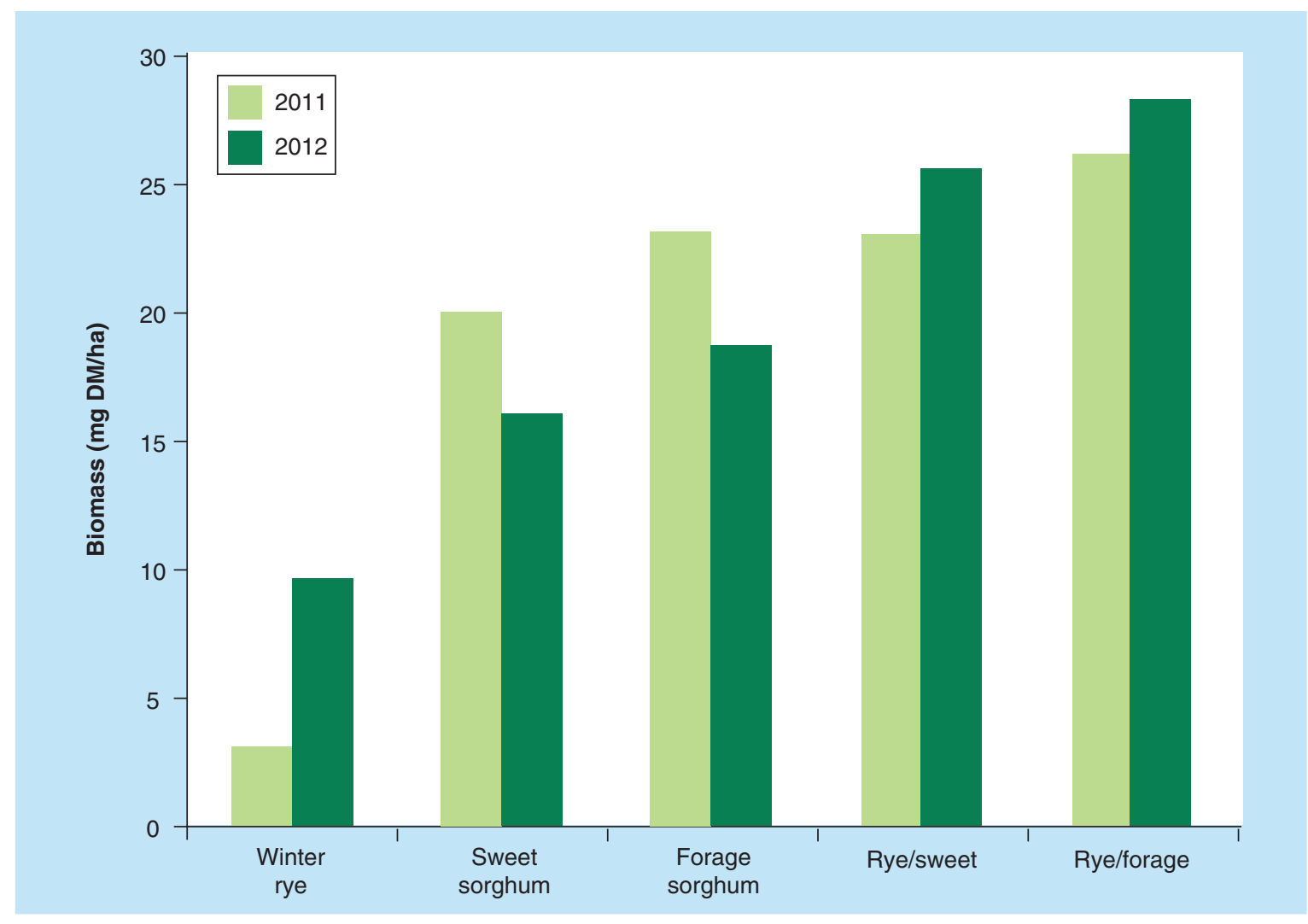

Figure 2. Biomass yield of winter rye, sweet sorghum and forage sorghum grown in central lowa (USA) during 2011-2012. The growing season in the latter year was characterized by drought and, although sorghum yields were reduced by lack of moisture, the losses were offset by more favorable growing conditions for the rye crop.

it significantly expands the annual period for effective capture and use of photosynthetic energy when compared with most current cropping practices (Figure 1). Double cropping is also a recognizable and perhaps more (i.e., producer) acceptable form of landscape management, which has been identified as an approach for integrating multiple bioenergy feedstock sources and biomass residuals into current crop production systems [22].

\section{Key terms}

Primary crop: Refers to the dominant crop or crops (e.g., corn and soybean) currently being grown in an area because of the relatively stable marketing systems, established cultural management practices and higher potential for profit than any other land use.

Secondary crop: Refers to any new or additional crop grown between periods that are optimum for primary crops and are added to a rotation to increase

income, achieve environmental benefits or diversify the established production system.

\section{Double cropping strategies}

One of the easiest double cropping strategies for producers to adopt would be to plant a small grain crop such as rye or triticale ( $\times$ Triticosecale Wittmack) in the fall and harvest it for biomass the following spring, before planting a cereal grain such as corn (Zea mays L.) or an oilseed such as soybean [23] (Figure 1). The grain crop would be the primary crop in this sequence because of the inflexibility imposed by the need for the crop to progress through pollination, fertilization and seed development. Management of the small grain does not require the crop to progress through these stages of development, and it can and should be harvested at a time to accommodate timely planting of the summer crop. Grain yield for no-till soybean following a rye crop in 2011 and 2012 near Ames (IA, USA) averaged 3.8 and $3.2 \mathrm{Mg} / \mathrm{ha}$ (56.9 and 47.3 bushels/acre), respectively. This was especially favorable for 2012 when very severe drought conditions occurred throughout much of the US Corn Belt.

A major concern with the use of bioenergy crops is that they may displace food crops, and have negative effects on food availability and costs. Double crop systems that include both a food crop and a bioenergy crop could reduce the potential of this occurring. Feyereisen et al. evaluated the use of winter rye in a double crop system with corn and soybean [23]. They concluded that in using this system, substantial potential exists for producing biomass feedstock without creating a negative impact on food production. Use of double cropping systems is a form of ecological intensification that will be necessary for meeting future demands for food [24] and fuel [25].

Another variation that may be adapted to the region, particularly in more northern areas, could be 
the production of a winter annual oilseed crop such as canola (Brassica napus L.) or camelina (Camelina sativa L.), followed by production of a summer annual biomass crop such as sorghum [26-28]. In this case, the winter oilseed crop would be considered the primary crop in the sequence. The secondary crop would be harvested for biomass at or after the end of the growing season regardless of the stage of development that has been achieved.

Perhaps the most manageable approach to double cropping bioenergy crops would involve growing two biomass crops grown in succession. In this case, timing of harvest for both crops is flexible, and decisions regarding when to harvest can be made based on soil and crop management considerations, such as weather and economics, rather than the biological necessity of allowing at least one of the crops to complete its growth cycle. Winter annual crops, such as triticale and rye, grown in a double crop sequence with sorghum or corn have been evaluated for this purpose and have demonstrated promise for biomass production.

\section{Crop growth \& production}

The potential relative growth rates of the two crops in a double crop sequence are rarely equal, with the winter annual crop having a much lower rate [29]. It is important then that the growing periods of the two crops do not overlap to any great degree, because of the loss of dry matter accumulation during the period in which the more productive crop is better adapted diminishes overall productivity. Under these circumstances, the gain in yield obtained from the second crop can be offset by loss of yield in the primary crop.

A growth analysis study conducted by Heggenstaller et al. in Iowa addressed this concern [30]. They compared growth parameters of corn grown as a single crop with that of corn grown in a double crop sequence with triticale. Their analysis was focused on total dry biomass production and did not consider grain production apart from its contribution to total biomass. Although higher leaf areas and corresponding maximum growth rates were observed in corn grown as a single crop, total combined yields were greater for the corn-triticale double crop. This occurred due to an increase in the leaf duration interval for the double crop system. Accordingly, dry matter accumulation occurred over an extended period of time in the double crop system, as compared with the single crop.

Other studies conducted on double cropping systems for biomass production have yielded varying results. In a study evaluating single-crop sorghum and sorghum grown in a double crop sequence with triticale, Goff et al. [17] found that double crop biomass yields were higher for early maturing sorghum varieties when combined with those of triticale, compared with those of a single crop of the same variety planted earlier in the season. However, for late maturing sorghum varieties, there was no yield advantage to the double crop system. This was attributed to the late-season growth of these sorghum genotypes, which remained green and continued to accumulate dry matter until frost. There was no yield advantage to growing these varieties in a double crop system, because doing so resulted in later planting and thereby restricted the period of time during which carbon fixation by sorghum occurred. When theoretical ethanol yield was predicted from chemical composition, all the sorghum varieties evaluated would have potentially produced more ethanol from a full season planting when compared with a double crop with triticale. Thus, the intended conversion process may play an important role in the decision to use a single versus a double crop system.

Photoperiod insensitive sorghum varieties will undergo reproductive development regardless of day length [31]. Those that are sensitive to photoperiod generally flower under very short day length and, thus, continue to grow vegetatively throughout most of the growing season in the northern Corn Belt. The ontogeny of these plants is qualitatively different than those that are insensitive to photoperiod. The latter generally progress through reproductive stages of development to produce viable seed and undergo senescence near the end of the growing season. Photoperiod sensitive varieties do not undergo or complete the transition to reproductive development, and those that do produce seed that is mostly immature [31]. As the work of Goff et al. demonstrates, the choice of the cultivar used in a double crop system is important and has leverage on the relative biomass yield produced [17]. The highest yielding systems evaluated by Goff et al. were all single crops of late maturing varieties that included forage, sorghum $\times$ sudangrass hybrids and sweet types [17].

In a companion study to the growth analysis study described above, Heggenstaller et al. compared the biomass yield of three double crop sequences to a single crop of corn [29]. The double crop sequences all included fall-planted triticale followed by corn, sorghum or sunn hemp (Crotalaria juncea L.). Yields of the double crop sequences that included corn and sorghum were higher than that of corn grown as a single crop, which yielded better than the double crop sequence with sunn hemp. The corn hybrid used in their study was adapted to the region and produced grain in both systems in which it was grown. It is possible, and perhaps likely, that a different result would have occurred had a tropical genotype that remained vegetative throughout the growing season been grown. Corn hybrids that are adapted to lower latitudes generally flower later in the northern Corn Belt and, similarly to the photoperiod sensitive 
sorghums described above, could potentially be used to increase singlecrop biomass yields at more northern latitudes [32].

A study conducted in Minnesota compared biomass production from double crop sequences of winter rye with corn with a single crop of corn [33]. The highest total biomass yield was achieved with a double crop of rye followed by corn $(9.6+16.3=25.9 \mathrm{Mg} / \mathrm{ha})$. However, the performance of the double crop system was quite variable over environments and, because of the risk involved, it was concluded that a single crop of corn was preferable to a double crop of winter rye and corn.

Another study conducted in Iowa demonstrated that double cropping has the potential for improving environmental outcomes, but concluded that any yield gains were likely to be offset by increased costs of production [34]. Double crops of rye and sweet sorghum were highly responsive to nitrogen fertilization and outperformed single crops of sorghum in some environments. Yields of double cropped rye and sorghum were improved when included in a 3-year rotation with corn and soybean. The researchers attributed this improvement to nitrogen carried over from the soybean crop. Use of a double crop system may therefore be more effective in increasing biomass yield as part of a longer rotation that includes soybean or another legume.

\section{Environmental benefits}

The inclusion of a winter annual crop in double crop systems offers a number of advantages in protecting and enhancing environmental quality. Cropping sequences that include a winter annual with a summer crop, such as corn, can greatly increase the duration of plant cover [35]. During periods of active plant growth biomass crops actively cycle nutrients from the soil to support new growth. Nutrients that are mobile in the soil, such as nitrate, are immobilized as they are incorporated into the growing plant. Extending the period of active growth by including a second crop proportionally increases the amount of nutrients that can be taken up by a crop and, thus, prevents their loss by leaching below the rooting zone of the crop. Nitrate and other nutrients that move freely with soil water can be leached into drainage systems that discharge effluent into surface water. They can also percolate into groundwater and potentially contaminate drinking water supplies. This problem is particularly acute in the corn/soybean belt where traditional cropping systems leave land fallow between fall harvest and spring planting. During this time, nutrient loading is often highest from natural transformation of organic nitrogen to nitrate (nitrification) and nitrogen fertilizer application. Because no crop is present to take up and immobilize nitrate, it is at higher risk of leaking from the system and contaminating surface and groundwater.
This is occurring at an alarming rate as evidenced by high nutrient loads entering the Mississippi river basin being discharged into the Gulf of Mexico and causing the development of a large hypoxic zone [36].

Double cropping enhances water quality by providing vegetative cover of the soil throughout the winter [29]. Vegetation produced by the winter annual crop in the fall prevents soil from eroding through interception of rainfall above the soil surface and root systems that stabilize the soil below. By intercepting precipitation and increasing infiltration, the winter annual crop reduces runoff that delivers suspended soil particles and dissolved nutrients to surface water. The movement of nutrients such as phosphorus that are bound to soil particles to surface water is also reduced by the presence of the winter annual crop [37].

Depending on the tillage system used, a double crop system may also contribute to long-term stability or improvement in soil quality. Increased input of organic carbon into the soil, coupled with a decrease in loss of nutrients and carbon due to erosion, could potentially result in an increase in soil productivity over time [38].

\section{Practical considerations for double cropping}

The cost of production is significantly greater for a double crop system. Establishment and management costs associated with the second crop must be considered in relation to any gain in production. It is clearly feasible to increase biomass productivity using a double crop while decreasing the overall efficiency of production. Moreover, the second crop may and often requires the use of different machinery, increasing the capital investment required. However, the use of a double crop can lower the average fixed cost of land because more products can be produced from the same area [37]. Realistically, it is unreasonable to expect widespread adoption of biomass double cropping systems until the financial returns are equal to or better than competing cropping systems.

At present, there are no real markets for lignocellulosic biomass. There are a few conversion plants operating at a modest scale and others are in development, but until marketing opportunities develop for biomass crops, producers are unlikely to implement double crop systems for growing it. However, if the targets set for advanced biofuels by the Renewable Fuel Standard are to be achieved, the development of such markets can be anticipated [39,40]. Once established, profitable marketing opportunities will spur the adoption of alternative cropping systems for biomass production.

From a grower perspective, the negatives of double cropping increase at higher latitudes because of a more contracted growing season. Unpredictable fall and spring weather often interferes with planting and harvest, and therefore increases risk associated with 
producing either crop. The secondary crop may also and often interferes with the production of the primary crop. Yield of corn, for example, is sensitive to planting date and delayed planting causes yield reductions [41]. Other summer annual crops may similarly be affected.

Weather can also interfere with planting and the presence of another crop that must be first removed exacerbates problems with planting. Current cropping systems are optimized to exploit the growing season and crops are planted as early as possible. Growers often hedge against the potential of unfavorable spring weather by completing seedbed preparation and fertilization the previous fall, if there is time before winter sets in. These operations, while not generally recommended for environmental reasons, are nevertheless commonly practiced for practical ones. Planting and growing a winter annual crop interferes with fall tillage and fertilization, and thus can affect timeliness in planting the summer crop.

Commodity crops grown in the corn/soybean belt are supported by genetic improvements and production technologies that are relatively mature compared with those presently available for energy crops. Moreover, they are supported by government farm programs that significantly reduce the risk of their production, to the extent that producers can almost be assured of avoiding a catastrophic loss. This is generally not true of many of the crops that might be used in double crop biomass production systems.

Other potential reasons that producers may be reluctant to use double crop management in more northern latitudes include the time and labor costs of establishing, managing and harvesting the lignocellulosic crop. Another reason is that producers may not be familiar with the new crop(s) and therefore lack knowledge regarding how to optimize their growth and development. Incorporating biomass crops into current grain-based rotations will require an investment of time and labor resources to make them successful. These additional crops will also consume soil water and nutrients unless they are replenished by reliable precipitation events and fertilizer nutrient management strategies. If these essential plant growth inputs are not properly managed, the primary grain crop will undoubtedly be negatively impacted, resulting in loss of yield and profit from that crucial investment. The current lack of proven and stable markets, as well as the lack of protection against potential grain crop losses through crop insurance or other programs, could be considered a social barrier to double crop biomass production systems.

Therefore, despite some successes in producing double crops of biomass, the stability of these systems is at present far less than the dominant grain crops and cropping systems. This variability in performance is often related to environmental effects, but more importantly reflects the relative immaturity in the development of double crop systems. Researchers are still trying to figure out which systems hold the most promise for producing double crops of biomass. Once the most promising crop species are identified, substantial research will be required to adapt and develop agronomic practices and cultivars specific to producing biomass. It will also be important for government programs to provide appropriate incentives for producing biomass using a double crop strategy. The environmental benefits that could be derived from doing so raise the hope that this will happen.

\section{Future perspective}

Emerging markets for biomass will create demand and opportunities for novel crop production strategies designed to deliver high quantities of feedstock. Biomass double cropping systems will most likely be deployed in areas where the provision of winter cover is needed to prevent runoff and leaching of nutrients.

When focusing on complex agricultural production systems that are being challenged to meet global food, feed, fiber and renewable fuel needs, double cropping is one strategy for enhancing landscape diversity. But why is diversity important? Simply stated, a diverse landscape provides multiple ecosystem services including: feedstocks for bioenergy; enhanced nutrient cycling; multiple pathways for sequestering carbon; food, feed and fiber resources; filtering and buffering processes; wildlife food and habitat; soil health, protection and security; as well as economic opportunities for humankind. If landscape management is so important, why is it a difficult concept for many people to grasp, and what barriers need to be overcome to implement it for sustainable bioenergy feedstock supplies and enhanced soil quality? This too is a very complex question, so perhaps illustrating landscape diversity as a 'wicked' problem is an appropriate way to show why conservation programs of today are so much more challenging than during past decades [2]. Wicked problems are those difficult to describe issues that are subject to considerable political debate [42]. Such problems tend to arise from civil society, not from experts, and they are often thrust upon policymakers and scientists. Wicked problems tend to have neither a clear definition nor an optimal solution, and attempts to solve them can easily cause the problem to change. Addressing wicked problems does not tend to lead to definitive 'solutions'. Instead, the action often results in outcomes that are simply 'better or worse'. In other words, wicked problems are not 'solved', but rather they are 'managed'.

Use of double cropping for sustainable bioenergy feedstock production is one of the potential agronomic strategies contributing to a balance between economic 
drivers and natural resource limiting factors (Figure 3). Among the economic drivers, double cropping could ensure a more stable supply of feedstock throughout the calendar year by more effectively capturing radiant energy, and making favorable use of soil and water resources to produce feedstock materials. A steady, consistent supply of feedstock with minimum periods of bare ground would overcome potential ecologically limiting factors that could minimize feedstock supplies, and also ensure that ecosystem services such as wildlife habitat and soil quality are not compromised [43].

Questions regarding exactly how double crop, lignocellulosic biomass production and wildlife habitat will interact provide an excellent example of why this proposed agricultural land management practice qualifies as a 'wicked' problem. As stated by Rupp et al., there are few robust scientific studies examining bioenergy production and wildlife communities [44]. However, the greatest consequences for wildlife will likely be highly correlated to any habitat alterations created by either converting existing agricultural landscapes to largescale bioenergy production or more intensive resource extraction from landscapes. A combination of resources (e.g., food, cover, water and space) and environmental conditions (e.g., temperature, precipitation, and presence of predators and competitors) arranged in such a way so as to promote occupancy by individuals or populations is needed for wildlife to survive and reproduce. Therefore, when effects of double crop feedstock production on wildlife populations are considered, direct impacts on species' resources, spatial arrangement of those resources, and shifts in inter- and intra-specific interactions that may lead to changes in survival and viability must be evaluated. It is also very likely that the specific effects will fluctuate greatly from site to site depending on several factors. We postulate that positive factors associated with double crop biomass production will include: a more diverse habitat; increased stubble height; increased landscape patchiness across the landscape; greater refuge areas; and provision of food during the winter. However, having to harvest at least twice each year could be a negative factor for some species. Undoubtedly, this topic warrants additional, detailed investigations by researchers specializing in wildlife ecology, but from an agronomic perspective, we maintain that double cropping biomass crops can provide many different lignocellulosic materials, each with its own unique advantages and disadvantages.

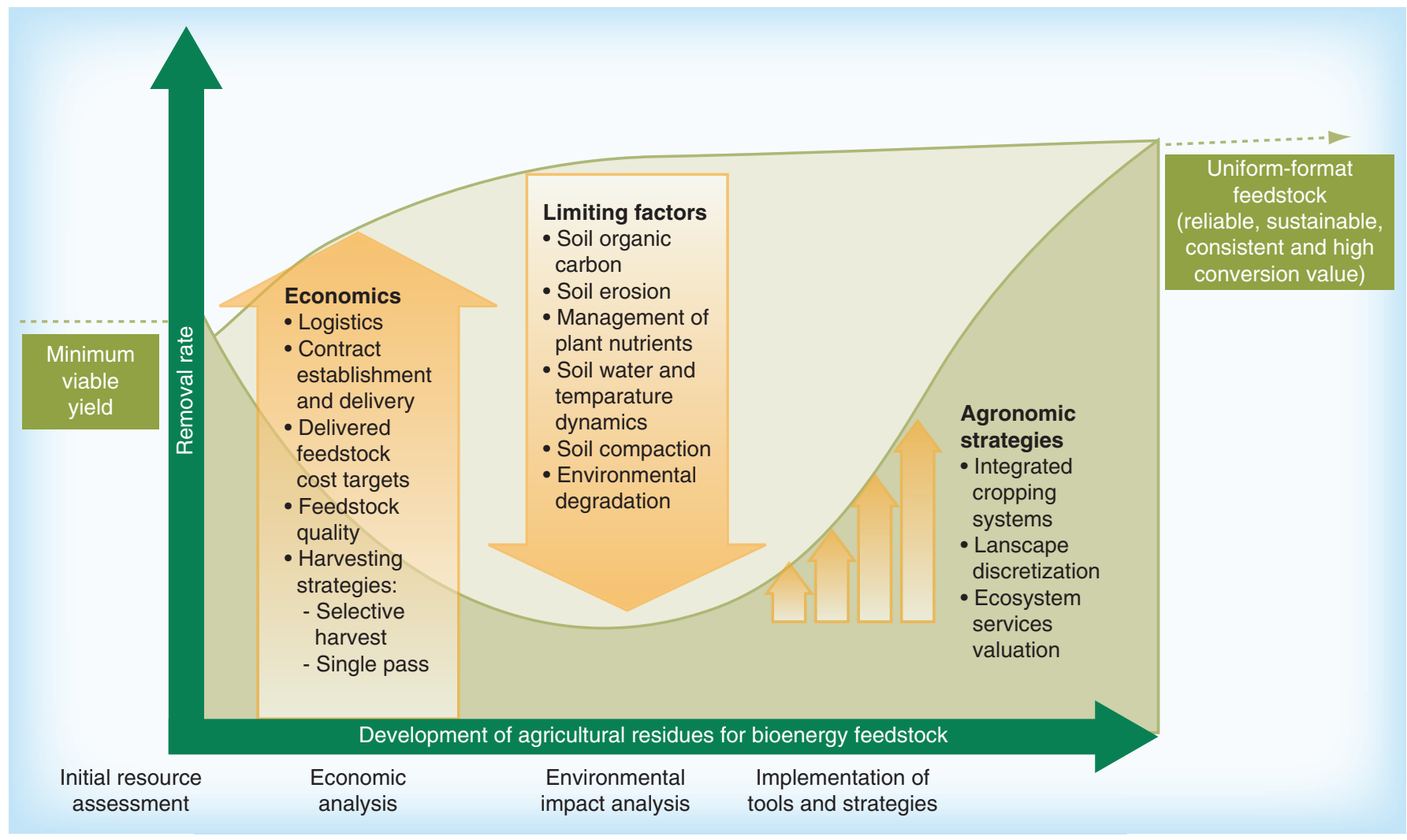

Figure 3. Competing economic drivers and environmental sustainability forces that must be balanced to achieve sustainable cellulosic feedstock supplies and support the transition from fossil to renewable fuels.

Reprinted with permission from [49] $\odot$ Industrial Biotechnology, Mary Ann Liebert, Inc. (2010). 
Climate change is anticipated to affect cropping systems throughout the world [45]. The length of the growing season throughout much of the US Corn Belt is likely to increase over the next several decades [46]. This, along with anticipated increases in precipitation of $5-15 \%$, should increase the geographical range within the region in which double cropping for biomass production is feasible.

In summary, agriculture has tremendous potential to help solve global energy challenges, but soil, water and air resources cannot be managed using rigid engineering practices or designs [47]. Natural resources are living and dynamic - constantly changing in response to natural and human-induced stresses. Therefore, regionally specific strategies are needed to ensure sustainable supplies of biomass crops to support development and operation of emerging biofuel and bioproduct industries. Double cropping in north central USA is just one specific example of the many strategies that need to be rigorously studied through comprehensive, multilocation research and education endeavors. Due to the past focus on grain production, information on double cropping in this region is limited but opportunities abound. The challenge is to work with our natural resource base, rather than attempting to control or overcome it. There is no single biomass crop, feedstock or production practice that will be desired or most effective for any region or the nation as a whole. Even at the watershed or field level, subunit management strategies are needed to ensure long-term sustainability [48]. It should also be recognized that double cropping of lignocellulosic biomass crops will become a reality only when processing facilities create a demand for them. Therefore, our goal is to stimulate interest and research focused on double cropping in this region, to support bioenergy and bioproduct industries that will be crucial for economic, environmental and social sustainability throughout the region.

\begin{abstract}
Financial \& competing interests disclosure
The authors have no relevant affliations or financial involvement with any organization or entity with a financial interest in or financial conflict with the subject matter or materials discussed in the manuscript. This includes employment, consultancies, honoraria, stock ownership or options, expert testimony, grants or patents received or pending, or royalties.

No writing assistance was utilized in the production of this manuscript.
\end{abstract}

\section{Executive summary}

\section{Background}

- Development of highly productive biomass energy crops and cropping systems is critical for meeting global demands for bioenergy.

Double cropping

- Double cropping biomass energy crops holds promise as a way of increasing biomass availability while sustaining the environment.

- Can be an effective strategy for exploiting the entire growing season, when producing winter annual and summer annual energy crops in succession.

Environmental benefits

- Double cropping can provide soil surface cover for greater time periods throughout the year, thus protecting the resource from the erosive forces of wind and water.

- Double cropping can result in improved water quality by providing nearly perennial soil cover that increases water infiltration and reduces runoff.

- By using crops that actively grow during spring, double cropping can reduce leaching of nitrate into groundwater by intercepting and immobilizing it.

- Double cropping also increases the amount of carbon added to the soil, thus helping to improve and/or sustain soil health and quality. Future perspective

- Double cropping biomass requires the development of new crop cultivars, agronomic practices and government programs that value soil conservation and other ecosystem services.

\section{References}

Papers of special note have been highlighted as:

- of interest

1 America's Energy Future Panel on Alternative Liquid Transportation Fuels, National Academy of Sciences, National Academy of Engineering, National Research Council. Liquid Transportation Fuels Form Coal and Biomass: Technological Status, Costs, and Environmental Impacts. National Academies Press, Washington, DC, USA, 322 (2009).
2 Rosillo-Calle F, Johnson FX. Food Versus Fuel: An Informed Introduction to Biofuels. Zed Books Ltd, London, UK, 217 (2010).

3 Laser M, Lynd L. Introduction to cellulosic energy crops. Chapter 1. In: Cellulosic Energy Cropping Systems. Karlen DL (Ed.). John Wiley \& Sons Ltd, Chichester, UK (2014) (In Press).
4 Xie H, Shen H, Gong Z, Wang Q, Zhao ZK, Bai F. Enzymatic hydrolysates of corn stover pretreatedd by a $\mathrm{N}$-methylpykrrolidone-ionic liquid solution for microbial lipid production. Green Chem. 14, 1202-1210 (2012).

5 Lynd LR, Wyman C, Laser M, Johnson D, Landucci R. Strategic Biorefinery Analysis: Review of Existing Biorefinery Examples. 
National Renewable Energy Laboratory, CO, USA (2005).

6 Karlen DL, Andrews SS, Wienhold BJ, Doran JW. Soil quality: humankind's foundation for survival. J. Soil Water Conserv. 58, 171-179 (2003).

7 Koch A, McBratney A. Global soil week: put soil security on the global agenda. Nature 492, 186 (2012).

8 Demirbas A. Political, economic and environmental impacts of biofuels: a review. Appl. Energy 86, S108-S117 (2009).

9 Rowe RL, Street NR, Taylor G. Identifying potential environmental impacts of large-scale deployment of dedicated bioenergy crops in the UK. Renew. Sust. Energ. Rev. 13, 271-290. (2009).

10 Anjum A. Biomass: energy and environmental concerns in developing country. Int. Res. J. Environ. Sci. 1, 54-57 (2012).

11 Skinner RH, Zegada-Lizarazu W, Schmidt JP. Environmental impacts of switchgrass management for bioenergy production. In: Switchgrass: A Valuable Biomass Crop for Energy. Monti A (Ed.). Springer-Verlag, London, UK, 129-152 (2012).

12 Tilman D, Socolow R, Foley J et al. Beneficial biofuels - the food, energy, and environment trilemma. Science 325, 270-271 (2009).

13 Kline K, Dale VH, Lee R, Leigy P. In defense of biofuels, done right. Issues Sci. Technol. 225, 75-84 (2009).

14 Dale BE, Bals BD, Kim S, Eranki P. Biofuels done right: land efficient animal feeds enable large environmental and energy benefits. Environ. Sci. Technol. 44, 8385-8389 (2010).

15 Perlack RD, Wright LL, Turhollow AF, Graham RL, Stokes BJ, Erbach DC. Biomass as Feedstock for a Bioenergy and Bioproducts Industry: The Technical Feasibility of a Billion-Ton Annual Supply. US Department of Energy, US Department of Agriculture, Washington, DC, USA (2005).

16 US Department of Energy. US Billion-Ton Update: Biomass Supply for a Bioenergy and Bioproducts Industry. US Department of Energy, Oak Ridge National Laboratory, TN, USA (2011).

17 Goff BM, Moore KJ, Fales SL, Heaton EA. Double-cropping sorghum for biomass. Agron. J. 102, 1586-1592 (2010).

- Study evaluating several sorghums grown as a monocrop or in a double-crop sequence with triticale.

18 Helsel ZR, Wedin WF. Harvested dry matter from single and double-cropping systems. Agron. J. 73, 895-900 (1981).
19 Natural Resources Conservation Service. Soil Taxonomy: A Basic System of Soil Classification for Making and Interpreting Soil Surveys (Second Edition). US Department of Agriculture Natural Resources Conservation Service, US Department of Agriculture, Washington DC, USA (1999).

20 Vogel KP, Schmer MR, Mitchell RB. Plant adaptation regions: ecological and climatic classification of plant materials. Rangeland Ecol. Manage. 58, 315-319 (2005).

21 Wiebe K. Linking Land Quality, Agricultural Productivity, and Food Security. Resource Economics Division, Economic Research Service, US Department of Agriculture, Washington, DC, USA (2003).

22 Brick S. Harnessing the Power of Biomass Residuals: Opportunities and Challenges for Midwestern Renewable Energy. Chicago Council on Global Affairs, Chicago, IL, USA, 6 (2011).

23 Feyereisen GW, Camargo GGT, Baxter RE, Baker JM, Richard TL. Cellulosic biofuel potential of a winter rye double crop across the U.S. corn-soybean belt. Agron. J. 105, 631-642 (2012).

- Modeling study evaluating the potential of winter rye as an energy crop grown in a double crop sequence with corn and soybean.

24 Cassman KG. Ecological intensification of cereal production systems: yield potential, soil quality, and precision agriculture. Proc. Natl Acad. Sci. USA 96, 5952-5959 (1999).

25 Gan Y, Malhi SS, Brandt S, KatepaMupondwa F, Kutcher HR. Brassica juncea canola in the Northern Great Plains. Agron. J. 99, 1208-1218 (2007).

26 Gesch RW, Archer DW. Double-cropping with winter camelina in the northern Corn Belt to produce fuel and food. Ind. Crops Prod. 44, 718-725 (2013).

27 Gesch RW, Cermak SC. Sowing date and tillage effects on fall-seeded camelina in the northern Corn Belt. Agron. J. 103, 980-987 (2011).

28 Bugbee BG, Salisbury FB. Exploring the limits of crop productivity. Plant Physiol. 88, 869-878 (1988).

29 Heggenstaller AH, Anex RP, Liebman M, Sundberg DN, Gibson LR. Productivity and nutrient dynamics in bioenergy doublecropping systems. Agron. J. 100, 1740-1748 (2008).

- Comparison of double crop sequences of corn, sorghum and sunn hemp grown in a double crop sequence with winter triticale.
30 Heggenstaller AH, Liebman M, Anex RP. Growth analysis of biomass production in sole-crop and double-crop corn systems. Crop Sci. 49, 2215-2224 (2009).

31 Maughan M, Voigt T, Parrish A, Bollero G, Rooney W, Lee DK. Forage and energy sorghum responses to nitrogen fertilization in central and southern Illinois. Agron. J. 104, 1032-1040 (2012).

- Growth analysis study of double crop systems emphasizing differences in crop growth parameters.

32 White WG, Moose SP, Weil CF, McCann MC, Carpita NC, Below FE. Tropical maize: exploiting maize genetic diversity to develop a novel annual crop for lignocellulosic biomass and sugar production. Chapter 11. In: Routes to Cellulosic Ethanol. Buckeridge MS, Goldman GH (Eds). Springer Science and Business Media, Berlin, Germany, 167-179 (2011).

33 Crookston RK, Fox CA, Hill DS, Moss DN. Agronomic cropping for maximum biomass production. Agron. J. 70, 899-902 (1978).

34 Buxton DR, Anderson IC, Hallam A. Performance of sweet and forage sorghum grown continuously, double-cropped with winter rye, or in rotation with soybean and maize. Agron. J. 91, 93-101 (1999).

- Very interesting study of double-crop systems in longer-term rotation with corn and soybean.

35 Kleinman PJA, Salon P, Sharpley AN, Saporito LS. Effect of cover crops established at time of corn planting on phosphorus runoff from soils before and after dairy manure application. J. Soil Water Conserv. 60, 311-322 (2005).

36 Goolsby DA. Mississippi Basin nitrogen flux believed to cause Gulf hypoxia. Eos Trans. AGU 81(29), 321-327 (2000).

37 Burton RO Jr, Crisostomo MF, Berends PT, Kelley KW, Buller OH. Risk/return analysis of double-cropping and alternative crop rotations with and without government programs. Rev. Agr. Econ. 18, 681-692 (1996).

38 Follett RF. Soil management concepts and carbon sequestration in cropland soils. Soil Till. Res. 61, 77-92 (2001).

39 Energy Policy Act of 2005. Public Law 109-158. US Government Printing Office, Washington, DC, USA (2005).

40 Energy Independence and Security Act of 2007. H.R. 6. US Government Printing Office, Washington, DC, USA (2007). 
41 Lauer JG, Carter PR, Wood TM et al. Corn hybrid response to planting date in the northern Corn Belt. Agron. J. 91, 834-839 (1999).

42 Batie SS. Taking conservation seriously as a wicked problem. In: Managing Agricultural Landscapes for Enviornmental Quality II. Achieving More Effective Conservation. Nowak P, Schnepf M (Eds). Soil and Water Conservation Society, Ankeny, IA, USA, 143-155 (2010).

43 Wilhelm WW, Hess JR, Karlen DL et al. Balancing limiting factors and economic drivers for sustainable midwest agricultural residue feedstock supplies. Ind. Biotechnol. 6 , 271-287 (2010).

44 Rupp SP, Bies L, Glaser A et al. Effects of Bioenergy Production on Wildlife and Wildlife
Habitat. Wildlife Society Technical Review 12-03. The Wildlife Society, Bethesda, MD, USA (2012).

45

Meza FJ, Silva D, Vigil H. Climate change impacts on irrigated maize in Mediterranean climates: evaluation of double cropping as an emerging adaptation alternative. Agric. Syst. 98, 21-30 (2008).

Walthall CL, Hatfield J, Backlund P et al. Climate Change and Agriculture in the United States: Effects and Adaptation. US Department of Agriculture 23 Technical Bulletin 1935, Washington, DC, USA (2013).

47 Karlen DL. Where to from here? In: Sustainable Feedstocks for Advance Biofuels: Sustainable Alternative Fuel Feedstock Opportunities, Challenges and Roadmaps for Six U.S. Regions. Braun R, Karlen D, Johnson
D (Eds). Soil and Water Conservation Society, Ankeny, IA, USA, 376-378 (2010).

48 Muth DJ, McCorkle DS, Koch JB, Bryden KM. Modeling sustainable agricultural residue removal at the subfield scale. Agron. J. 104, 970-981 (2012).

49 Wilhelm WW, Hess JR, Karlen DL et al. Balancing limiting factors and economic drivers for sustainable midwestern US agricultural residue feedstock supplies. Ind. Biotechnol. (New Rochelle NY) 6(5), 271-287 (2010).

\section{- Website}

101 Department of Energy, Idaho National Laboratory. Leaf technology. www.inl.gov/LEAF 